\title{
Peer Teaching in Medical Education: Highlighting the Benefits and Challenges of Its Implementation
}

\author{
Verona Sukrajh, and Adegoke O. Adefolalu
}

\section{ABSTRACT}

Peer teaching is an educational strategy that embraces active learning, it explores the social dynamics and interactions as well as the communication and interpersonal skills that influence learning. Embedded within peer teaching as an educational strategy are several theories which promote active learning. It is very important to have a good understanding of the various philosophies underpinning the learning process, because of the numerous variables that have to be considered in order to make the implementation of peer teaching a successful exercise in the context of medical education. Based on the outcome of an extensive literature review together with field experience of the authors, the focus of the current paper will be to highlight the benefits and challenges that should be anticipated by medical educators who want to introduce peer teaching into their teaching and learning activities as part of innovation that would enhance active learning among their students.

Keywords: peer teaching, medical education, medical students, educational strategy, active learning
Published Online: February 18, 2021

ISSN: $2736-4534$

DOI : 10.24018/ejedu.2021.2.1.52

\section{Dr V. Sukrajh}

Practice of Medicine (POME) Unit, School of Medicine, Sefako Makgatho Health Sciences University, South Africa e-mail: verona.sukrajh ${ }^{\circledR}$ smu.ac.za

\section{Dr AO Adefolalu*}

Practice of Medicine (POME) Unit, School of Medicine, Sefako Makgatho Health Sciences University, South Africa e-mail: adegoke.adefolalu@smu.ac.za

*Corresponding Author

\section{INTRODUCTION}

Medical education is revolutionizing with a change in focus from teaching to learning [1], necessitating a transformation from the outdated instruction-paradigm to the contemporary learning-paradigm. In which case the medical schools are responsible for providing learning rather than providing mere instructions [2]. To engage students in the process of learning demands interactive instructional techniques which involves students doing things and reflecting on what they are doing [3]. Therefore, the popular saying that "Learning is not a spectator sport" still holds true up till today [4]. In the Flexner report that was compiled more than 100 years ago, he asserted that "Modern medicine like all scientific teaching is characterized by activity, the student no longer merely watches and listens, memorizes while learning, he does [5]". Through the exploration and application of several adult learning theories in modern contemporary medical education, it is clear that the perceptions of both the student and the teacher needed to change. Meaning that the student takes responsibility for their own learning and the teacher becomes a mere facilitator for the student's learning process [6]. Effectively, the role of the teacher therefore has to change dramatically from just presenting knowledge to facilitating and guiding the students' learning experience in a manner that allows them to be actively involved in their own learning process [7]. At the turn of the 21 st century there was an urgent call on all stakeholders involved in medical education for a reform in medical education to promote health care professionals to be educated through active learning, engaging in critical thinking and maintaining higher ethical conduct. This fundamental shift require proven strategies guided by transformative learning model, where the focus is shifted from fact memorization to searching, analysis and synthesis of information [8]. One of the educational strategies that has shown to have such potential in enhancing the skills of active learning among medical students is called peer teaching. It is an educational strategy that embraces active learning, it explores the social dynamics and interactions as well as the communication and interpersonal skills that influence learning. Embedded within peer teaching as an educational strategy are several theories which promote active learning.

The concept of peer teaching, the premise of peer assisted learning is not new and has been used widely in medical education [9]. Peer teaching can be defined broadly as: "People of similar social groups who are not professional teachers helping each other to learn and learning themselves by teaching". Peer teachers are students who teach fellow students [10]. Lecturing is still a dominating teaching strategy, even though research indicates its limitation in learning, However, traditional lectures can be modified to active learning engagements without the loss of content [11]. The term peer teaching may seem clear in its definition, but it is not just a single undifferentiated educational strategy. Its complexity is demonstrated in the variety of teaching and learning employed in this context [12]. The literature reveals several types of peer teaching in higher education and its development through the years.

Outlined below are the three dimensions in practice into which peer teaching can be classified [9]. 
Distance between the student and the peer teacher: This distance is based on the stage of training. The stage of training can be equal or at the same level and is known as peer teaching. When there is a difference of levels where peer teaching is from an advanced level of training, this is referred to as near peer teaching.

Group size of students taught: The size of the group of students taught requires different approaches to teaching in the spheres of knowledge, skills and attitudes. The group sizes can vary from one-to-one peer teaching or peer tutoring, small group settings or large group settings.

Formality of teaching: The formality of the teaching encounter can range from informal to formal. Students could work together informally by assisting each other in preparation for assessments or explaining difficult concepts for better understanding. Within a formal dimension, students could be required to replace the teachers by providing lectures or serve as teachers for problem-based learning session [9].

There is a great diversity in the terminology and definitions of types of peer teaching that is based on the different approaches, historical origins, academic disciplines and countries in which peer teaching was developed [13]. With the wide variety of different arrangements that need to be considered in the design of peer teaching within a curriculum, attention to the organizational aspects of the implementation is extremely important for optimal learning to occur. The table shown below (Table 1) captures the different terminology most frequently used in current literature.

\section{IMPLEMENTATION OF PEER TEACHING}

Over the last three decades the focus of several research work has been the outlining of the organizational variables for the delivery of peer teaching. One of such framework was developed by some authors which classified them into thirteen variables [14], as enumerated below.

\section{A. Curriculum content:}

This includes the knowledge or skills or combination to be covered in the curriculum.

\section{B. Contact constellation.}

The dynamics of the ratio of peer teacher to the group of students can vary. At times there could be one peer teacher who can have between 2 to 30 or more in a group of students.

\section{Within or between institutions:}

Most peer teaching occurs within institutions however it can also take between different institutions or for example between universities and schools.

\section{Year of study}

The distance between the peer teacher and the student can vary between the same or different levels.

\begin{tabular}{|l|l|l|l|l|}
\hline $\begin{array}{l}\text { Examples of the different } \\
\text { arrangements }\end{array}$ & Distance & $\begin{array}{l}\text { Group } \\
\text { size }\end{array}$ & Formality & \multicolumn{1}{|c|}{$\begin{array}{c}\text { Terminology used in } \\
\text { literature }\end{array}$} \\
\hline $\begin{array}{l}\text { Students work together to } \\
\text { prepare for a test, } \\
\text { rehearsing with each other }\end{array}$ & Low & Low & Low & $\begin{array}{l}\text { Peer assisted learning (PAL) } \\
\text { Peer counselling } \\
\text { Cooperative learning }\end{array}$ \\
\hline $\begin{array}{l}\text { Personal coaching by an } \\
\text { experienced senior }\end{array}$ & High & Low & Low & $\begin{array}{l}\text { Near peer tutoring } \\
\text { Near peer mentoring }\end{array}$ \\
\hline $\begin{array}{l}\text { Senior medical students } \\
\text { rehearse within groups of } \\
\text { junior medical students }\end{array}$ & High & High & High & Near peer teaching \\
\hline $\begin{array}{l}\text { Residents function as } \\
\text { formally scheduled tutors } \\
\text { or mentors }\end{array}$ & High & Low & High & $\begin{array}{l}\text { Near peer tutoring } \\
\text { Near peer mentoring }\end{array}$ \\
\hline $\begin{array}{l}\text { Teaching assistants in lab } \\
\text { classes or skills training: } \\
\text { residents as group } \\
\text { teachers }\end{array}$ & High & High & High & $\begin{array}{l}\text { Near peer teaching (within the } \\
\text { same level of training) } \\
\text { Cross level teaching (different } \\
\text { level of training) }\end{array}$ \\
\hline $\begin{array}{l}\text { Student organized } \\
\text { extracurricular, voluntary } \\
\text { group activites }\end{array}$ & High & High & Low & \\
\hline $\begin{array}{l}\text { Students take turns to } \\
\text { teach their small group }\end{array}$ & Low & High & High & $\begin{array}{l}\text { Reciprocal teaching } \\
\text { Co-teaching }\end{array}$ \\
\hline $\begin{array}{l}\text { Scheduled dyad tasks } \\
\text { within a lecture or small } \\
\text { group sessions }\end{array}$ & Low & Low & High & $\begin{array}{l}\text { Peer assisted learning } \\
\text { Co-tutoring } \\
\text { Reciprocal tutoring } \\
\text { Teaching dyads } \\
\text { Peer monitoring }\end{array}$ \\
\hline $\begin{array}{l}\text { Senior students or } \\
\text { residents counsel junior } \\
\text { students in clinical } \\
\text { clerkships }\end{array}$ & Low & Low & Low & $\begin{array}{l}\text { Student mentoring } \\
\text { Peer modelling } \\
\text { Peer coaching }\end{array}$ \\
\hline
\end{tabular}

Fig 1. Peer teaching terminology in different arrangements. [9]

\section{E. Ability}

This may be divided between cross ability or same ability basis. The peer teacher may have a superior mastery over a small part of the curriculum or may be of equal ability but steering towards a deeper understanding.

\section{F. Role continuity:}

The role of a peer teacher does not to be permanent. All students can be a peer teacher by switching roles strategically.

\section{G. Time}

Peer teaching can be embedded into regular class time or outside class time. It could also include a combination of both.

\section{H. Place:}

The location of peer teaching could vary enormously.

\section{Helper characteristics:}

There is an assumption that the peer teachers need to be best students, which is not always true. The use of average or weak students as peer teachers can be beneficial to the learning of the peer teaching.

\section{J. Characteristics of the helped:}

The students taught by the peer teacher could be anyone, or they could be students who underachieve or fail due to difficulties.

\section{K. Objectives}

This may target cognitive or intellectual gains, academic achievements, affective and attitudinal gains, social and emotional gains, self-image or self-concept gains or any combination.

\section{Voluntary or compulsory}

Some tasks are voluntary and others compulsory. 


\section{Reinforcement:}

There could be extrinsic rewards such as marks or certificates for the peer teachers. Research indicates that providing extrinsic reinforcement does not damage intrinsic reinforcement.

\section{FACTORS INFLUENCING THE LEARNING PROCESS IN PEER TEACHING}

There are several areas of learning that can be promoted by adopting the peer teaching strategy, therefore, there are many benefits to be derived from using peer teaching model in medical education. It is also important to sound a note of caution about the some of the possible challenges associated with peer teaching in real life practice. Highlighted below are some of the benefits of adopting the peer teaching approach in enhancing active learning among students as mentioned in the literature.

\section{Cognitive Benefits of PeER Teaching}

In this peer teaching educational strategy, there is a concept called the "teacher - learner duality" meaning that a person assumes the dual roles of being a teacher and a learner at the same time, allowing the individual to relate teaching with learning and in the process getting a better understanding of teaching which may result in the teacher becoming a better learner in the process [15]. In addition, the engagement of the peer teacher stimulates learning through the preparation to teach, as this demands that the student who is acting as a peer teacher has to reflect and constantly assimilate new information into their existing knowledge base, as they continue to challenge their own existing knowledge to accommodate the new information acquired to enable them to reach a state of equilibrium [10]. Furthermore, if one were to consider the process of learning from the self-explanation effect, which prescribes that students are required to explain the knowledge they acquired first to themselves, and then to others. It has shown that such student often showed a greater understanding of the knowledge in question compared to when they merely receive the explanation from another person. Therefore, teaching continue to serve as a powerful instrument in the learning process [9].

When learning through the teaching process, the peer teacher is again challenged because the knowledge needs to be simplified, clarified and exemplified [10,16]. To fully explain a concept to another individual, one first needs to have a full understanding and truly grasped the knowledge content, in other words embodying and crystallizing one's thought into a language that would be appropriate in communicating the concept to one's audience [14]. According to the literature, the ability to communicate and articulate content knowledge of what is required to be taught to other people provides the peer teacher with insight of whether students understood what they have studied or not. [12]. The cornerstone of peer teaching is the cognitive congruence that exists between the teacher and learner, this is explained under the cognitive congruence theory which stipulates that teachers with a knowledge base similar to that of the students are often more effective in their teaching compared to others $[9,17]$. This assertion is also well supported by the Vygotsky's school of thought, which also affirms that for learning to be optimized, the distance between what is known and what is still to be learnt is just enough to stimulate active inquiry, and this lies within the zone of proximal development [14]

\section{Metacognitive Benefits of Peer Teaching}

Peer teaching promotes students to take responsibility for their learning which encourages the development of their metacognitive skills [18]. Through the progression of peer teaching begins a self-awareness of reflecting and accurately assessing one's own learning strategies. This enables the student to self-regulate and self-monitor their learning approaches, which can lead to adapting more effective strategies which can be applied to different contexts [14-15].

\section{Motivational And EMotional IMPACT OF PEER TEACHING ON LEARNING}

Peer teaching enhances the intrinsic motivation in students due to the conditions, which evoke the emotions of competence, autonomy and relatedness that are honed when in the role of a teacher as compared to being in a role of a passive learner [9]. The active participation of students makes learning more autonomous. This encourages interactions through discussions and feedback, thereby increasing the relatedness amongst students. Furthermore, students are intrinsically motivated when they take on such responsibility by actively participating in their learning [19]. Peer teaching has also been shown to improved self-confidence among students who engage in teaching other student, this is evident in a situation where an individual is placed in certain position where the person adapts their perception of themselves in accordance with what is expected of such position. Therefore, whenever a student is asked to adopt the role of a teacher, this will always lead to increased self-confidence and belief in their own expertise on the part of the student within the context of carrying out some of the roles of a teacher [9].

\section{ENHANCING COMMUNICATION AND INTERPERSONAL SKILLS THROUGH PEER TEACHING}

One of the significant skills that is usually acquired by students who engage in peer teaching is good communication skills which students can utilize throughout their career [20]. There is plenty of evidence in the literature that supports this assertion, many of them from empirical research which revealed that peer teaching is a strategy that could enhance communication and interpersonal skills among students, especially after their involvement in peer teaching activities which also make them active learner. One of this study done among some students also shown that students who had prior experience with peer teaching displayed more sensitivity in the area of interpersonal communication compared to those who have never been involved [21].

\section{COMMUNICATION AND INTERPERSONAL SKILLS}

Communication is an essential and core clinical skill that assists a doctor to interact positively with a patient, but in essence communication is usually limited to what is said and not how, to whom or when they say it. Interpersonal skills capture the latter elements that contain the emotional content of the dialogue though this skill still lacks a common 
language and conceptualization in medical education [22]. The focus in a medical curriculum is usually on interactions with patients, however, an emerging aspect includes clinical teamwork with peers and colleagues. Communication skills and interpersonal skills deal with aspects of speaking up to supervisors, clarity in assuring the sequence of the message and attention to roles and relationships, monitoring and backup. These skills are generally learnt through the hidden curriculum or sometimes not at all [23]. The value of communication and interpersonal skills has gained sufficient importance to shift from the hidden curriculum. This is currently specified as a competency in the medical curriculum which clarifies what is effective in the transfer of information with patients and their families, but also includes peers in their profession. This has been further reinforced and outlined in CanMEDS [24], embedding this skill permanently within the medical curriculum. Communication skills have been outlined as the ability to listen effectively, to obtain information through effective questioning, present information using explanatory skills that are effective, to be able to counsel and educate patients and to have the ability to make informed decisions using the patient's information and preferences. Interpersonal skills require a doctor to be able to build and to maintain a beneficial relationship and furthermore, to also display respect and caring behaviours [23]. Identifying communication and interpersonal skills as a core competency is a significant step forward, however, teaching and assessing these skills still remains a challenge [25].

\section{CReAting A Positive LeARning ENVIRONMENT}

Research has shown that students' perceptions of their learning environment have great influence on their learning, therefore, a favorable learning environment, which encourages closeness amongst the students and a community of learning which is full of positive emotional energy is bound to promote active learning among the students [26]. In terms of the social congruence theory, this kind of environment promotes learning due to the trusting relationship that exists among the student's peers, in addition, the social congruence theory goes further to emphasize the absence of hierarchy between the students and the peer teachers as the main reason why such a trusting relationship exists in the first place. Since the peer teachers are also students themselves, there is no reason for any mistrust to exist between the two groups in a conducive learning environment where all the students fully understand the essence of engaging in peer teaching activities. Therefore, the students feel less threatened and are able to admit to any of their ignorance and misconceptions that could manifest during the peer teaching exercise, allowing for them to be corrected and to get further clarifications. This creates better understanding for the students and at the same time enable them to appreciate the usefulness of the peer teaching technique in medical education. Invariably, as a result of this conducive learning environment, students are able to subsequently engage in deeper active learning with their peers as they form strong relationships among themselves which allows them to freely explore concepts, learn to listen and critique each other without the presence of any formal authority [12].

\section{Challenges In Peer Teaching}

The value of peer teaching as an effective learning strategy is compelling, however there are a few challenges stated in the literature that could hinder the learning process. The planning and implementation of peer teaching may unveil potential pitfalls, which may require review and alterations of certain aspects along the way. To avoid some of these pitfalls, it is important to arrange appropriate stakeholders, pay attention to the training of the peer teachers, and to also clarify the practical arrangements that are necessary for the success of the peer teaching [27]. In one of the research that aimed to elucidate the perception of the students on the benefit of peer teaching, despite the fact that learning was enhanced by the social and cognitive congruence, the students were still concerned that peer teachers may not reflect the knowledge of an experienced expert in the field [28]. Furthermore, in a less formal teaching environment, the peer teacher always have difficulty taking control of the group as they were taken less seriously. This also impacted their objectivity when evaluating and assessing their peers. In light of the above-mentioned challenges, some of the students have suggested that they should be given some kind of training on how to teach for effective group learning, and also be guided on how to handle the difficulties that often arise during peer teaching. Another factor that may be obstructive to the peer learning process is social loafing. Social loafing or free riding is when members within a group shirk their responsibilities in the hope of gaining from others in the group [29]. This causes a threat to the positive interdependence within a group. Usually this occurs when the group size is too large and group members are not identifiable or group members are not evaluated individually. This problem could be addressed by evaluating and providing feedback to each individual within the group rather than given the entire group a general feedback [30].

\section{CONCLUSION}

Peer teaching is an educational strategy that embraces active learning, it explores the social dynamics and interactions as well as the communication and interpersonal skills that influence learning. Embedded within peer teaching as an educational strategy are several theories which promote active learning. It is very important to have a good understanding of the various philosophies underpinning the learning process, because of the numerous variables that one has to consider in order to make the implementation of peer teaching a successful exercise in the context of medical education. The social construct of peer teaching creates a complex learning environment which challenges the students at a cognitive, affective and metacognitive level of learning. Furthermore, students have the opportunity to confront their own communication and interpersonal skills, which are clearly uncovered in their interactions during peer teaching. In the current paper, addressing each component separately has provided an in-depth understanding that guided the rationale behind the call for the peer teaching approach to be introduced as a learning strategy that has the potential to enhance the students' ability to learn actively. 


\section{COMPETING INTERESTS}

No conflict of interest is associated with this manuscript.

\section{REFERENCES}

[1] DE. Karakitsiou, A. Markou, P. Kyriakou, M. Pieri, M. Abuaita E Bourgousis, T. Hido, A. Tsatsaragkou, A. Boukali, C. de Burbure and IDK. Dimoliatis. The good student is more than a listener: The $12+1$ roles of the medical student. Medical Teacher, vol. 34, pp. 1-8, 2012.

[2] RB. Bagg, and J. Tagg. From learning to teaching - A new paradigm for undergraduate education. Change, vol. 27, no. 6, pp. 12-25, 1995.

[3] CC. Bonwell, and JA. Elison. Active learning: creating excitement in the classroom. George Washington University. Ashe-Eric Higher Education Report 1, Washington DC, 1991.

[4] AW. Chickering, and ZF. Gamson. Seven principles for good practice. American Association for Higher Education (AAHE) Bulletin, vol. 39, pp. 3-7. 1987.

[5] A. Flexner. Medical Education in the United States and Canada, Bulletin Number Four. The Carnegie Foundation for the Advancement of Teaching, New York, 1910.

[6] DCM. Taylor, and H. Hamdy. Adult learning theories: Implications for learning and teaching in medical education: AMEE Guide No 83. Medical Teacher, vol. 35, pp. e156-e1572, 2013.

[7] RS. Grabinger, and JC. Dunlap. Rich environments for active learning: a definition. Association for Learning Technology Journal, vol. 3, no. 2, pp. 5-34, 1995.

[8] J, Frenk, L. Chen, ZA. Bhutta, J. Cohen, N. Crisp, T. Evans, H. Fineberg, P. Garcia, Y. Ke, P. Kelley, B. Kistnasamy, A. Meleis, D Naylor, A. Pablos-Mendez, S. Reddy, S. Scrimshaw, J. Sepulveda, D. Serwadda, and H. Zurayk. Health professionals for a new century: transforming education to strengthen health systems in an interdependent world. The Lancet, vol. 376, no. 9756, pp. 1923-1958, 2010 .

[9] O. Ten Cate, and S. Durning. Dimensions and psychology of peer teaching in medical education. Medical Teacher, vol. 29, no. 6, pp. 546$552,2007$.

[10] KJ. Topping. The effectiveness of peer tutoring in further and higher education: A typology and review of the literature. Higher Education, vol. 32, pp. 321-345, 1996.

[11] B. Graffam. Active learning in medical education: Strategies for beginning implementation. Medical Teacher, vol. 29, pp. 38-42, 2007.

[12] D. Boud, R. Cohen, and J. Sampson. Peer learning in higher education: learning from and with each other. Kogan Page, UK, 2001.

[13] MT. Ross, and S. Cameron. Peer assisted learning: a planning and implementation framework: AMME Guide No 30. Medical Teacher, vol. 29, pp. 527-545, 2007.

[14] KJ. Topping, and S. Ehly. (Eds.). Peer-assisted learning. Mahwah NJ and London UK: Lawrence Erlbaum, 1998.

[15] M. Dandavino, L. Snell, and J. Wiseman. Why medical students should learn how to teach? Medical Teacher, vol. 29, pp. 558-565, 2007.

[16] JM. Lockyer, CS. Hodgson, T. Lee, S. Faremo, B. Fisher, W. Dafoe, V. Yin, and V. Claudo. Clinical teaching as part of continuing professional development: does teaching enhance clinical performance. Medical Teacher, vol. 38, pp. 815-822, 2016.

[17] TM. Lockspeiser, P. O'Sullivan, A. Teherami, and J. Muller. Understanding the experience of being taught by peers: the value of social and cognitive congruence. Advances in Health Science Education, vol. 13, pp. 361-372, 2008.

[18] M. Stigmar. Peer to peer teaching in higher education: a critical literature review. Mentoring and tutoring: Partnership in learning, vol. 24, no. 2, pp. 124-136, 2016.

[19] RA. Kusurkar, G. Croiset, and THJ. Ten Cate. Twelve tips to stimulate intrinsic motivation in students through autonomy supportive classroom teaching derived from self-determination theory. Medical Teacher, vol. 33, pp. 978-982, 2011.

[20] M. Manyama, R. Stafford, E. Mazyala, A. Lukanima, N. Magele, BR. Kidenya, E. Kimwaga, S. Msuya and J. Kauki. Improving gross anatomy learning using reciprocal peer teaching. BMC Medical Education, vol. 16, pp. 95, 2016.

[21] CL. Chou, DE. Masters, A. Chang, M. Kruidering and KE. Hauer. Effects of longitudinal small group learning on delivery and receipt of communication skills feedback. Medical Education, vol. 47, pp. 10731079, 2013.

[22] L. Dyche. Interpersonal skill in medicine: the essential partner of verbal communication. Society of General Internal Medicine, vol. 22, pp. 1035-1039, 2007.

[23] Duffy, F.D., Gordon, G.H., Whelan, G., Cole-Kelly, K. \& Frankel, R. 2004. American Medicine. 79(6):495-507.

[24] Frank, J.R., Snell, L. \& Sherbino, J. (Ed). CanMEDS 2015 Physician Competency Framework. Royal College of Physicians and Surgeons of Canada, Ottawa, 2015.

[25] JN. Modi, AJ. Chhatwal, P. Gupta, and T. Singh. Teaching and assessing communication skills in medical undergraduate training. Indian Pediatrics. vol. 53, no. 6, pp. 497-504, 2016.

[26] SJ. Wayne, SA. Fortner, JA. Kitzes, C. Timm, and S. Kalishman. Cause and effect? The relationship between student's perception of the medical school learning environment and academic performance on USMLE Step 1. Medical Teacher, vol. 35, pp. 376-380, 2013.

[27] M.T. Ross, and S. Cameron, S. Peer assisted learning: a planning and implementation framework: AMME Guide No 30. Medical Teacher, vol. 29 , pp. 527-545, 2007.

[28] C. Bulte, A. Betts, K. Garner and S. During. Student teaching: views of student near-peer teachers and learners. Medical Teacher, vol. 29, no. 6 , pp. 583-590, 2007.

[29] P. Aggarwal. Social loafing on group projects structural antecedents and effect on student satisfaction. Journal of Marketing Education, vol. 30, no. 3, pp. 255-264, 2008.

[30] D.M. Torre, C. van der Vleuten, and D. Dolmans. Theoretical perspectives and applications of group learning in Problem-based learning. Medical Teacher, vol 38. pp. 189-195, 2016.

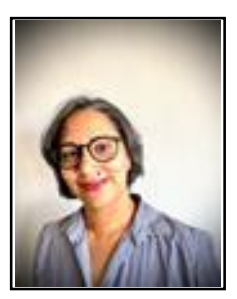

Dr Verona Sukrajh is a certified medical educator and has been involved in undergraduate medical education for over 10 years, especially in the aspect of teaching and learning, skills development, and curriculum development. She is currently a senior faculty at the School of Medicine, Sefako Makgatho Health Sciences University in South Africa, where she teaches HIV/AIDS Epidemiology, Communication skills and other competencies required of a medical graduate. She holds BSc (Hons), MBCHB degree, Diploma in HIV Management (SA), and MPhil (Health Professions Education) from Stellenbosch University. Dr Sukrajh interests include Innovative Teaching techniques, Curriculum development, Assessment modalities, and Peer-teaching in medical education. She is a member of the university's Curriculum Development Committee (CDC), and the Academic Planning \& Curriculum Review Committee (APCDC). Furthermore, she is a general practitioner focusing on preventative health care and health education.

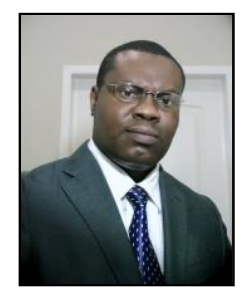

Dr Adegoke O. Adefolalu, (MBCHB, DipHIV Man (SA), MPH, PhD, FRSPH) is a faculty currently with the School of Medicine at the Sefako Makgatho Health Sciences University, South Africa, where he teaches Epidemiology and Research Methods within the Practice of Medicine integrated curriculum of the MBCHB programme. A Public health physician with special interest in medical education, some of his research interests include clinical epidemiology, HIV/AIDS, health systems, health behaviour and health determinants. An established researcher, Dr Adefolalu has published extensively in peer-reviewed journals, functioned as associate editor for multiple scientific journals, and has been serving as reviewer for many scientific journals for over 10 years. He is a fellow of the Royal Society of Public Health (UK), and a member of the Royal Society of Tropical Medicine and Hygiene. An astute health advocate, he mentors both staff and students, and he is actively involved in faculty development. 